\title{
STRIDOR IN INFANTS : A STUDY
}

\author{
H. Ramesh ${ }^{1}$, S. Ramesh ${ }^{2}$, S. Somasekhara Rao ${ }^{3}$
}

${ }^{1}$ Assistant Professor, Department of ENT, Rajiv Gandhi Institute of Medical Sciences, Srikakulam, Andhra Pradesh.

${ }^{2}$ Assistant Professor, Department of ENT, Rajiv Gandhi Institute of Medical Sciences, Srikakulamm, Andhra Pradesh.

${ }^{3}$ Assistant Professor, Department of Paediatrics, Rajiv Gandhi Institute of Medical Sciences, Srikakulam, Andhra Pradesh.

ABSTRACT: Stridor is a high-pitched noisy breathing produced due to partial obstruction of either larynx or in the trachea. It may also be the first sign of a life threatening disorder. So, stridor in infants should not be overlooked or minimized as an inconsequential finding. Stridor is a distressing symptom to its victims and their parents and presents a diagnostic challenge to the otolaryngologist.The team work of otolaryngologist, pediatrician, anesthesiologist and other specialty people in the evaluation and management of the stridor. The aims of this study is thorough evaluation to uncover the precise underlying causes of stridor in infants. Which in turn helps in the management. In this study total 17 infants with stridor were evaluated for the etiology, and the causes are Laryngomalacia 9cases, Unilateral vocal cord palsy, Bilateral vocal cord palsy, Subglottic web, Subglottic hemangioma each 1 case and the acquired causes are foreign bodies in trachea one and larynx two ,post intubation injury one case.

KEYWORDS: Stridor, Infants, Laryngomalacia.

HOW TO CITE THIS ARTICLE: H. Ramesh, S. Ramesh, S. Somasekhara Rao. "Stridor in Infants : a Study". Journal of Evolution of Medical and Dental Sciences 2015; Vol. 4, Issue 92, November 16; Page: 15746-15748, D0I: 10.14260/jemds/2015/2274.

INTRODUCTION: Stridor is a high-pitched noisy breathing produced due to partial obstruction of either larynx or in the trachea ${ }^{1}$. Stridor may be congenital or acquired, acute, intermittent or chronic. The phase of Inspiratory, Expiratory, or Biphasic Stridor may indicate the level at which the airway is compromised ${ }^{2}$.Stridor is a clinical sign and not a diagnosis. The golden standard in the evaluation of stridor is endoscopic examination under general anaesthesia.,4 Various aetiological causes of stridor in Infants were listed below. ${ }^{5}$

AIM OF THE STUDY: Aim of this study is identification of the cause of the stridor in infants. Identification of the cause of stridor is important because specific treatment can be offered and prognosis depends on the type and cause of the anatomical and functional abnormality present.

MATERIALS AND METHODS: The present study was conducted for about 23 months between August 2008 to July 2010 on 17 patients who was attending to ENT OPD and the cases referred to us from Pediatrics Department. The recruits were aged up to one year who came to us, with Mild to severe Stridor. We excluded cases of Streator, which is a sound produced due to obstruction in the nose, nasopharynx, and oropharynx. ${ }^{6}$ Before starting the study of patient's first priority is to assess the severity of stridor. If there is any air way compromise, first thing to do is to establish airway, by means of tracheostomy. After this only the process of evaluation of stridor begins.

Financial or Other, Competing Interest: None.

Submission 26-10-2015, Peer Review 27-10-2015,

Acceptance 05-11-2015, Published 14-11-2015.

Corresponding Author:

Dr. S. Ramesh,

Assitant Professor,

Rajiv Gandhi Institute of Medical Sciences,

Srikakulam, Andhra Pradesh.

E-mail: rameshseepana@rediffmail.com

DOI:10.14260/jemds/2015/2274.
The study of stridor in infants is done with the help of: Careful history taking: A proper history provides useful information on the differential diagnosis, severity, and level of obstruction. ${ }^{7}$

Thorough physical examination: The child should be inspected from head to feet. Most of the findings will to be seen in Head, neck and chest region. A marked head retraction is a feature of upper respiratory infection. Extension of neck reduces stridor in laryngomalacia. Signs of increased airway resistance to be looked for are.

1. Flaring of nostrils.

2. Any accessory muscles acting during inspiration.

3. In drawing of trachea (tracheal tug).

4. Any suprasternal in drawing.

5. Any intercostals in drawing.

6. Sub strenal in drawing.

7. Tachypnea, cyanosis.

Lab studies: Routine blood investigations \& ESR is helpful in assessing for the presence of an infection. Blood culture studies helpful in acute epiglottis to ensure correct antibiotic therapy is instituted.

The single most important laboratory test of respiratory efficiency in the critically ill child is measurement of arterial, blood gas levels. The $\mathrm{P}_{\mathrm{a}} \mathrm{O}_{2}$ indicates the level of oxygen being delivered to the tissues. Serious tissue hypoxia results when the $\mathrm{P}_{\mathrm{a}} \mathrm{O}_{2}$ falls below $6.65 \mathrm{kPa}(50 \mathrm{~mm} \mathrm{Hg})$. The $\mathrm{PaCO}_{2}$ is the best indicator of alveolar ventilation.

Imaging studies: Radiographic evaluation should begin with plain films. Anteroposterior and lateral radiographic views of the neck are useful for evaluating the assessment of epiglottic size and shape, retropharyngeal profile and subglottic and tracheal anatomy. They are also useful in the detection of radio-opaque foreign body

Endoscopy: Most infants with stridor require endoscopy to visualize the anatomical cause of stridor. 
DISCUSSION: This is a study of Stridor in infants conducted in the dept. of E.N.T. For about 23 months between August 2008 to July 2010. The present study, mainly a clinical study, was undertaken on patients of stridor between ages from the birth to 1 year of age. Total of 17 patients were studied during this period amongst who below 1 month of age were 3 patients, other 14 patients were aged between 2 months to 1 year.

Most of the patients were males (10 patients). Foreign bodies were common in Males (All 3 were male patients). vocal cord palsy was common in Females (2 patients were female). Incidence of Laryngomalacia is more or less equal in both with slight male predominance ( 5 male and 4 female).

8 out of the 17 patients presented with chronic stridor i.e. after 1 month of duration. 6 patients were presented with in a week of onset of stridor.

Foreign Bodies in Trachea and glottis, subglottic hemangioma, bilateral abductor palsy and post intubation injury were the cases presented with acute stridor. Birth history was abnormal in two cases. They presented with left vocal cord palsy and bilateral abductor palsy.

13 patients out of 17 were presented with congenital causes of stridor:

They are:

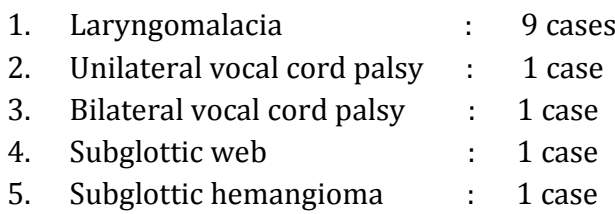

4 patients presented with acquired causes of stridor:

1. Foreign Bodies in Trachea : 1 case

2. Foreign Body Glottis : 2 cases

3. Post intubation injury : 1 case

Associated congenital anomalies were seen in some cases. Meningocele was associated with bilateral abductor vocal cord palsy. Pectusexcavatum was associated with two cases of laryngomalacia. In this study most commonly the lesion was identified in the larynx, amongst which supraglottic lesion namely laryngomalacia was the commonest observation. ${ }^{8,9}$ Glottic lesions observed were vocal cord palsy, Foreign Bodies (Whistle, stone) between two vocal cords.

Sub glottis lesions observed were web, and subglottic hemangioma. Both glottis and sub glottis involved in one case of post intubation injury. One foreign body was removed from Trachea. All the children in this study with stridor were evaluated by Radiological tests and by direct examination by endoscopy. Plain X-Ray of neck lateral view, revealed foreign body in the glottis.

CT scan is helpful in one case like subglottic web. Direct examination of larynx and trachea by rigid as well as flexible endoscopy was invaluable for evaluation of cause of stridor and useful to know the extent of lesion. In all the cases endoscopy revealed the cause and site of the lesion.

Tracheostomy was required for 7 children for following cases:

Foreign Body Trachea and Glottis : 3

Post intubation injury $\quad: 1$
Subglottic web $\quad: 1$

Sub Glottic hemangioma $\quad: 1$

Bilateral abductor palsy $\quad: \quad 1$

one child died in our study with bilateral abductor palsy with meningocoele.

\section{CONCLUSION:}

1. In this study of "stridor in infants", stridor is common mainly in males.

2. Congenital lesions are more common than acquired cause of stridor.

3. Laryngomalacia is the commonest cause followed by foreign bodies in the airway and vocal cord palsy.

4. Endoscopy is the gold standard for evaluation of stridor in infants.

5. Radiology has limited screening role in the evaluation of stridor in infants. ${ }^{10}$

The best treatment outcomes result when there is good cooperation and communication among otolaryngologists, pediatricians and anesthesia

\section{REFERENCES:}

1. Zoumalan R, Maddalozzo J, Holinger L D. Etiology of stridor in infants.

Ann Otol Rhinol Laryngol 2007; 116 (5): 329-34.

2. Bew S. Acute and chronic airway obstruction. Anaesth Intensive Care Med 2006; 7: 164-8.

3. Albert D, Leighton S. Stridor and airway management. In: Cummings CW, Fredrickson JM, Harker LA, KrauseCJ, Schuller DE, Rhichardson MA, Eds. Paediatric Otolaryngology, Head and Neck Surgery. 3rd ed. Mosby Year-Book Inc, Mosby, St Louis; 1998:285-302.

4. Wong Birgitta Yee-Hang, 1 Hui Theresa, 2 Lee So-lun, 3 HoWai-Kuen, 1 and Wei William Ignace1 Stridor in Asian Infants: Assessment and Treatment ISRN Otolaryngology Volume 2012, Article ID 915910, 4 pages.

5. Seth M. Pransky and Lawrence M. Simon, Clinical Evaluation of Stridor, HANDBOOK OF PEDIATRIC OTOLARYNGOLOGY; 2012, 183-219.

6. Bailey BJ, Calhoun KH ,Healy GB, Head \& Neck otolaryngology $3^{\text {rd }}$ ed. Philadelphia, P A:Lippincott, Williams,\&wilkins;2001.

7. A. Boudewyns, J. Claes, and P. van de Heyning, "Clinical practice: an approach to stridor in infants and children," European Journal of Pediatrics, vol. 169, no. 2, pp. 135141, 2010.

8. Holinger L D. Etiology of stridor in the neonate, infant and child. The Annals of Otology, Rhinology, and Laryngology 1980; 89 (5 Pt 1): 397 - 400.

9. Cotton RT, Reilly J S. Congenital malformations of the larynx. In: Bluestone C D, Stool S E, eds. Pediatric Otolaryngology. Vol 2. Philadelphia: W.B. Saunders; 1983: $1300-1$.

10. Tostevin PM, de Bruyn R, Hosni A,Evans JN. The value of radiological investigations in the pre-endoscopic assessment of children with stridor. J Laryngol Otol. 1995; 109:844-848. 


\begin{tabular}{|c|c|}
\hline Congenital & Acquired \\
\hline Larynx & Trauma \\
\hline Supraglottis & $\begin{array}{c}\text { thermal and chemical } \\
\text { injury }\end{array}$ \\
\hline Laryngomalacia & external injury \\
\hline Bifid epiglottis & intubation injury \\
\hline Web & Surgical \\
\hline Saccular cyst & foreign body \\
\hline Cystic hygroma & Laryngeal \\
\hline laryngocoele & Tracheal \\
\hline Glottis & Bronchial \\
\hline Atresia & Esophageal \\
\hline Web & Inflammatory \\
\hline cri-du-chat syndrome & acute laryngitis \\
\hline vocal cord paralysis & Laryngotracheobronchitis \\
\hline Sub glottis & \\
\hline Web & \\
\hline Stenosis & Allergy \\
\hline Hemangioma & angioneurotic edema \\
\hline Laryngotracheal cleft & \\
\hline Trachea and bronchi & \\
\hline Web & \\
\hline stenosis & \\
\hline Tracheomalacia & \\
\hline vascular compression & \\
\hline Mediastinal tumours & \\
\hline & \\
\hline
\end{tabular}

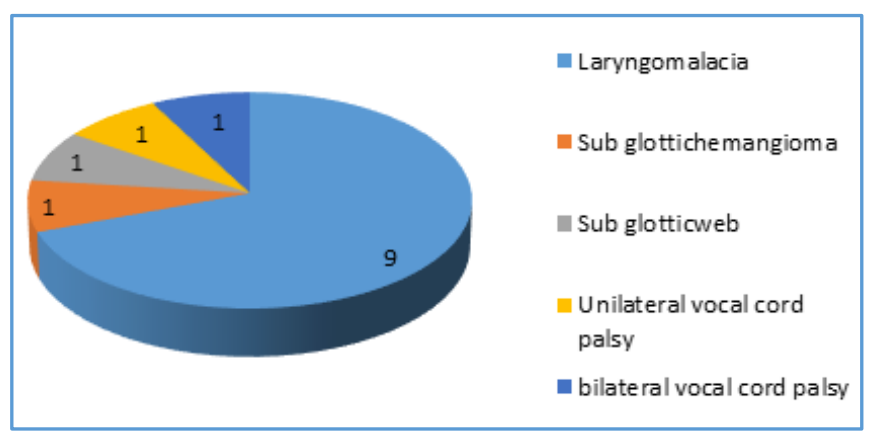

\begin{tabular}{|c|c|}
\hline Age Group & No. of Patients \\
\hline $0-1$ month & 3 \\
\hline $2-12$ months & 14 \\
\hline Total No. & $\mathbf{1 7}$ \\
\hline \multicolumn{2}{|c|}{ Age Distribution } \\
\hline
\end{tabular}

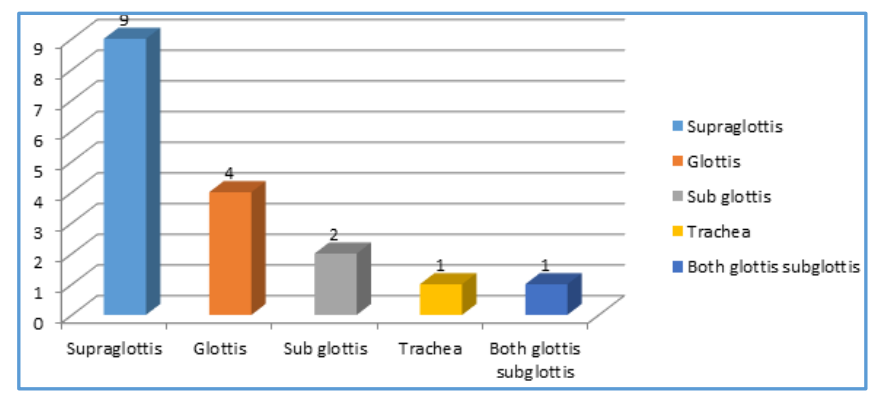

\begin{tabular}{|c|c|c|}
\hline \multirow{2}{*}{ Age } & \multicolumn{2}{|c|}{ No. of Patients } \\
\cline { 2 - 3 } & Male & Female \\
\hline $0-1$ month & 1 & 2 \\
\hline $2-12$ months & 9 & 5 \\
\hline Total & $\mathbf{1 0}$ & $\mathbf{7}$ \\
\hline \multicolumn{3}{|c|}{ Sex Distribution } \\
\hline
\end{tabular}

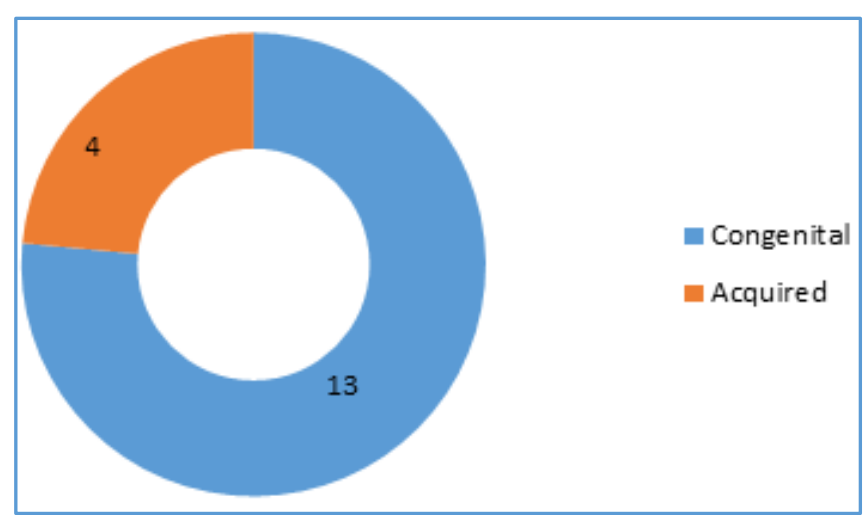

Site of Lesion 